Gadagkar,R. (2010). In love with Ropalidia marginata : 34 years, and still going strong. In: Social Behaviour: Genes, Ecology and Evolution (Eds.) Tamas Szekely, Allen J. Moore and Jan Komdeur, Cambridge University Press, Cambridge, pp. 85-87.

\title{
PROFILE
}

\section{In love with Ropalidia marginata: 34 years, and still going strong}

\author{
Raghavendra Gadagkar
}

While interviewing potential candidates for our departmental PhD programme every year, I usually ask the candidates what they would like to work on if they had complete freedom in the matter. Some years ago an unusually determined student gave me a firm answer: he wished to work on lesser cats, asking whatever questions he might be able to and using whatever methods that might work. I tried to argue with him, reminding him that lesser cats were extremely hard to study - they were nocturnal, shy and difficult to locate, let alone observe and obtain quantitative data on. Why not work on an easier animal with which you can ask more sophisticated questions, I pleaded. No, he was adamant lesser cats it would be, if he had any choice at all. His determination has stayed in my memory ever since. Other students have given me other kinds of answers, though I can recall none as determined as the young man in love with lesser cats. Some students gave primacy to the research field or question and were quite flexible about the study animal and methods to be employed. Others were sold on a method such as computer simulations or field biology, but were quite catholic about the exact questions or of the model organism.

No one has taught me more than students, and their various answers have given me much food for thought concerning the sociology of science. How do people choose what topic to study, what animal to use and what methods to employ, and how should they choose? As a result of much brooding spurred by the responses of students that I interview every year, I have crystallised my personal prejudice as follows: the research question should come first, and then one should choose a model organism that is best suited to the question. Methods should come last, and should be slaves at the service of the question and the animal, rather than the masters that dictate what we do.

Nevertheless, I must confess that the research question and the model animal are hard to prioritise. I think this is primarily because, though of greater importance, the question is abstract and kind of 'dead', but the study animal is alive and often rather cute. It is hard not to fall in love with your study animal. But is that a bad thing? I don't know - but I have been in love with my study animal for over 30 years, and no harm seems to have come of it so far.

I am interested in social evolution, and I study the tropical, Old World, primitively eusocial wasp, Ropalidia marginata. And boy, isn't it a beautiful wasp? I have been stung dozens of times but never complained. I guess that's what love does to you. I once had a letter from a fellow wasp researcher who said that he had just arrived in the Philippines, and had the great pleasure of being stung by Ropalidia for the first time in his life! But of course the real beauty of $R$. marginata comes from its utility as a study organism. The genus Ropalidia itself is unique and remarkable, comprising both primitively eusocial and highly eusocial species with unparalleled diversity in colony sizes and social biology. 


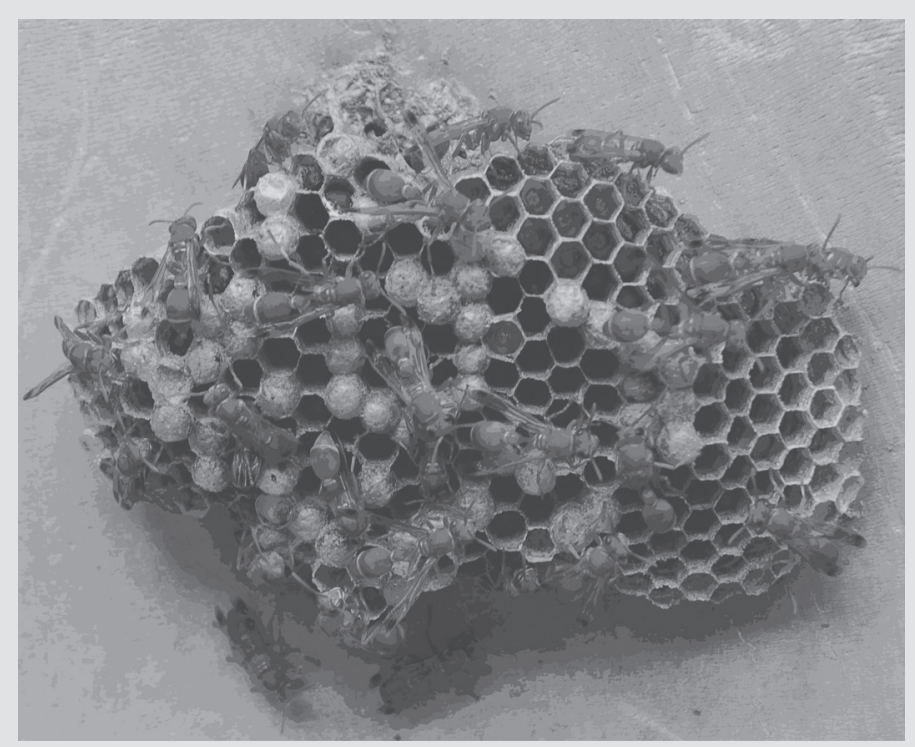

A typical nest of the primitively eusocial wasp Ropalidia marginata. Photo: Thresiamma Varghese.

There are two quite different ways of utilising the power of the genus Ropalidia to unravel the mysteries of social evolution. One is to capitalise on the diversity within the genus and undertake comparative studies of different species, a method of great power in modern evolutionary biology. The other is to concentrate on a single species and conduct detailed analyses of cooperation and conflict and assess the costs and benefits of social life. I have chosen the latter option, which is of course an important reason for my developing such an affinity for my study animal.

Indeed, $R$. marginata has turned out to be a providential choice. Its small colony size, absence of morphological caste differentiation, coexistence of single and multiple foundress associations, multiple behavioural options available to eclosing females, all make $R$. marginata ideally suited for investigating the evolutionary forces that promote social life. But what makes R. marginata even more special is that its tropical address makes possible a perennial indeterminate nesting cycle with mortal wasps forming potentially immortal colonies with frequent turnover of workers and occasional turnover of queens, providing a perpetual stage for these wasps to play out their games of war and peace. If $R$. marginata has been priceless in investigating the evolutionary causes of sociality, it has been even more crucial in understanding the proximate mechanisms that make social life possible. Unlike those of other primitively eusocial wasps, queens of $R$. marginata are remarkably meek and docile individuals, raising questions about how they manage to become queens and maintain their reproductive monopoly, how they suppress worker reproduction and regulate the non-reproductive activities of their workers.

Answers to these questions are being constantly revealed, as I now have a team of students similarly smitten by the beauty of $R$. marginata. We have shown that $R$. marginata queens begin their careers as very aggressive individuals and gradually lose their aggression as they develop their ovaries and establish themselves as undisputed leaders of their colonies. This seems possible because, on the one hand, they appear to use non-volatile pheromones 
to suppress worker reproduction and, on the other hand, workers regulate their own non-reproductive activities in a decentralised, self-organised manner. All this raises the question of the function of aggression, which is not absent from the social life of these wasps. We may just have hit upon at least two novel functions of aggression in this remarkable species. In summary, it appears that $R$. marginata is perhaps the most advanced among the primitively eusocial wasps studied so far, providing as a bonus the insight that such characteristics of highly eusocial species as pheromonal regulation of reproduction and self-organised work regulation can arise even before increased colony size and morphological caste differentiation.

While these discoveries come in unabated, it seems most unreasonable for me to switch to the study of any other species, in spite of the lure of many fascinating species that my surroundings are endowed with. It is unlikely that I will ever find any reason to abandon my first love. I must confess that we do turn from time to time to the congeneric Ropalidia cyathiformis - but I keep emphasising, much to the chagrin of my students, who devote themselves to the latter, that my only interest in $R$. cyathiformis is in using it to better understand $R$. marginata!

This claim is easy to substantiate. $R$. cyathiformis turns out to be a typical text-book example of a primitively eusocial species. Its queens are impressively aggressive, occupying the alpha position in the colony's peck order, and appear to suppress worker reproduction through physical aggression and regulate worker foraging through centralised top-down control. The more we show the world that R. cyathiformis behaves like a typical primitively eusocial species even in our own hands, the more credible our unusual claims about $R$. marginata will be, thus justifying my slogan ' $R$. cyathiformis in the service of $R$. marginata'.

\section{References}

Gadagkar, R. (2001) The Social Biology of Ropalidia marginata: Toward Understanding the Evolution of Eusociality. Cambridge, MA: Harvard University Press. 